\title{
The influence of different storage technologies on large power system frequency response
}

DOI:

10.1109/IPEMC.2016.7512295

\section{Document Version}

Accepted author manuscript

Link to publication record in Manchester Research Explorer

\section{Citation for published version (APA):}

Adrees, A., Song, J., \& Milanovic, J. V. (2016). The influence of different storage technologies on large power system frequency response. In Power Electronics and Motion Control Conference (IPEMC-ECCE Asia), 2016 IEEE 8th International https://doi.org/10.1109/IPEMC.2016.7512295

\section{Published in:}

Power Electronics and Motion Control Conference (IPEMC-ECCE Asia), 2016 IEEE 8th International

\section{Citing this paper}

Please note that where the full-text provided on Manchester Research Explorer is the Author Accepted Manuscript or Proof version this may differ from the final Published version. If citing, it is advised that you check and use the publisher's definitive version.

\section{General rights}

Copyright and moral rights for the publications made accessible in the Research Explorer are retained by the authors and/or other copyright owners and it is a condition of accessing publications that users recognise and abide by the legal requirements associated with these rights.

\section{Takedown policy}

If you believe that this document breaches copyright please refer to the University of Manchester's Takedown Procedures [http://man.ac.uk/04Y6Bo] or contact uml.scholarlycommunications@manchester.ac.uk providing relevant details, so we can investigate your claim.

\section{OPEN ACCESS}




\title{
The Influence of Different Storage Technologies on Large Power System Frequency Response
}

\author{
Atia Adrees, Member, IEEE, Jia Song and Jovica V Milanović, Fellow, IEEE \\ School of Electrical and Electronic Engineering \\ The University of Manchester \\ Manchester, U.K. \\ atia.adrees@.manchester.ac.uk,milanovic@manchester.ac.uk
}

\begin{abstract}
This paper investigates the contribution of energy storage systems to the system frequency response in a large meshed transmission system. The case studies compare the contribution of two types of energy storage technologies, i.e., battery energy storage system (BESS) and flywheel energy storage system (FES), to improve frequency response in the test network. Case studies examine the effect of different type of disturbance on frequency response in the presence of each type of storage technology. The effect of one bulk energy storage and distributed energy storage systems of the same capacity on frequency response of the power system is also investigated.
\end{abstract}

Keywords-Battery energy storage system; Frequency response; Flywheel energy storage system; Distributed energy storage

\section{INTRODUCTION}

The integration of renewable energy source (RES) reduces the dependence of fossil fuels and greenhouse gas emission, but augments the uncertainty and variability in the electric power generation. The active power dispatched and consumed should be balanced at every instant to keep the system frequency within a tight tolerance bounds. For example, in the UK, National Grid (the transmission system operator) has license obligation to maintain the system frequency within $\pm 0.2 \mathrm{~Hz}$ under normal conditions and $\pm 0.5 \mathrm{~Hz}$ in exceptional circumstances. In order to have safe and reliable power system operation, it is vital to have sufficient generation and demand that are held in automatic readiness to respond to the situation which may result in frequency variations. The initial frequency drop or increase depends on the system inertia. The primary frequency control spans 1-10s, achieved by speed governors. Secondary control, automatic generation control (AGC) takes tens of seconds to tens of minutes to re-dispatch the generations and bring frequency back to nominal value.

The increasing replacement of traditional power plants by renewable energy sources (RES) is leading to more challenging power system operation and requires additional balancing power. Energy storage technologies with fast response capabilities can provide frequency support within seconds. The

This work is supported by Engineering and Physical Sciences Research council (EPSRC) and China collaborative project RESTORES applications of battery energy storage system, flywheel energy storage system and super-capacitor have already been realized around the world for frequency regulation [1]. Many studies have been carried out to demonstrate the effectiveness of energy storage for primary frequency control and power smoothing of renewable energy sources (RES) [2]-[7].

Battery energy storage system has received substantial attention and is a relatively mature technology. Many studies have proposed different battery models and demonstrated the effectiveness of BESS on frequency regulation [2]-[4]. The result presented in [2] show that a BESS with simple control can effectively reduce frequency oscillations caused by sudden small load disturbances. In conventional power system, synchronous generation is controlled to damp the frequency oscillation following a load disturbance. It is demonstrated in [3] that a BESS with simple control is able to provide a better performance for LFC in a small interconnected power system with reliability and accuracy. Paper [4] adopted the voltage source battery model and proposed a control approach for optimal sizing of BESS to perform primary frequency control in a microgrid. Promising results demonstrated the effectiveness of the proposed control scheme.

Flywheel energy storage system is becoming popular due to its high efficiency, long life, and reliability. Studies performed in [5] and [6] use FESS to smooth the wind plant output. Studies carried out in [5] demonstrate that a FESS with power rating of 1.3 MVA installed next to a 5.8 MVA wind plant can significantly smooth the frequency and active power delivered to the external grid. It was demonstrated in [7] that the introduction of the FESS enhances the system stability and improves the power quality in an integrated power system following different network disturbances- generators outages, step increase or decrease in loads, and short circuit events.

This paper presents first comparative analysis of contribution of two types of energy storage technologies (BESS and FESS) to frequency response in large meshed power system. Frequency response of the system is monitored 


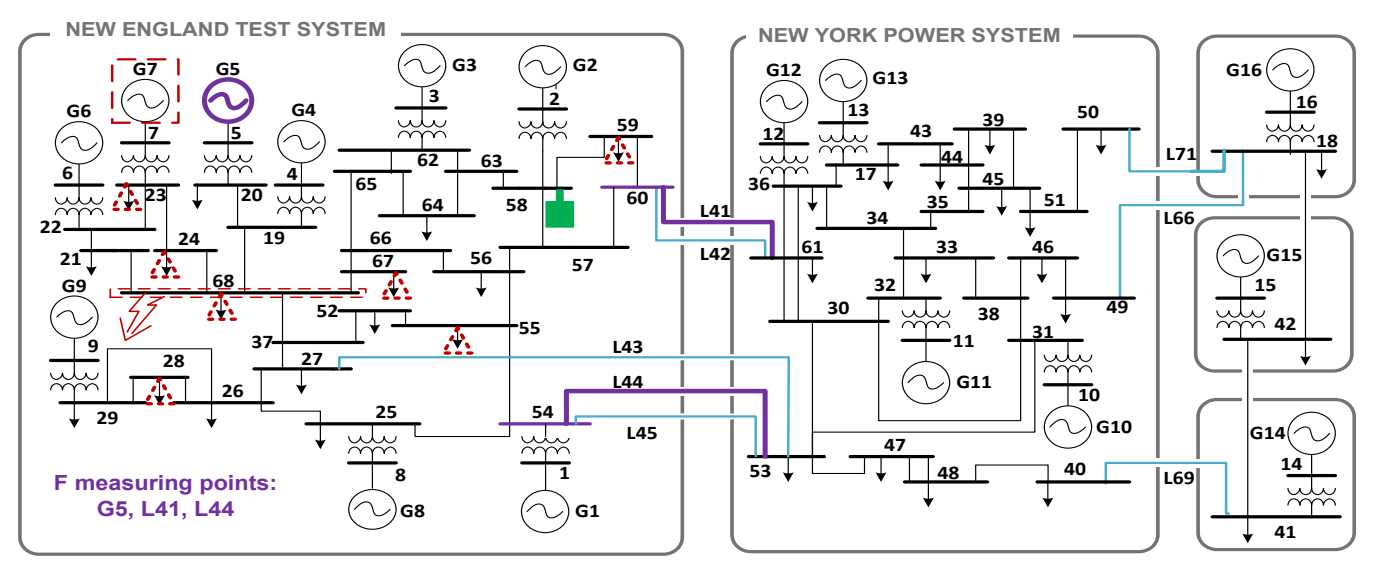

Fig. 1: IEEE16 machine, 68 bus network

following different types of disturbances, i.e., generator outage, three phase fault and increase or decrease in various loads.

Case studies are also performed to include the effect of the operating condition of the network on the system frequency response in the presence of energy storage system (ESS). The analysis is further extended to investigate the effect of different modes of deployment of storage on frequency response, i.e., single bulk energy storage and distributed energy storage in the network.

\section{Modelling And CONTROL OF StORAGE Systems \\ A Flywheel Energy Storage System (FESS)}

A FESS consists of flywheel, electrical machine and bidirectional power converting system [8]. Energy in FESS is stored in form of kinetic energy. The conversion of kinetic energy to electrical energy is achieved by a variable speed electrical machine connected to the flywheel. The electrical machine in FESS can be represented by permanent magnet synchronous machine (PMSM), doubly fed induction generator (DFIG) and cage induction machine [5]-[7]. In this work, DFIG with secondary excitation is considered as FESS [6],[9]. Flywheel energy storage system used within these studies is presented in Fig. 2. The secondary AC excitation system provides adjustable speed control, independent and fast control (produce/absorb) of active and reactive power. Since a flywheel is a rotating mass connected to the machine rotor, therefore, it can be modelled as an additional inertia coupled to DFIG [10], [11]. A FESS unit with 1.8-10 MVA power capacity usually has inertia constant ranging from $10-40 \mathrm{~s}$ [5], [6]. Therefore, the inertia constant of the 4 MVA FESS unit is chosen to be $15 \mathrm{~s}$ for this study. In order to connect the FESS to the transmission network, the two step up transformers are used. The energy available in FESS is proportional to the square of rotor speed given by (1)

$$
E=\frac{I\left(\omega_{\max }^{2}-\omega^{2}\right)}{2}
$$

$E$ is energy available in flywheel, $I$ is inertia constant, $\omega_{\max }$ is maximum flywheel speed, $\omega$ is current flywheel speed.

The maximum and minimum speed of the flywheel is taken in the range of $1.25-1.3 \mathrm{p} . \mathrm{u}$ and $0.7-0.75 \mathrm{p} . \mathrm{u}$ [5], [6]. In this work the maximum speed and the minimum speed are chosen to be 1.3 p.u and 0.7 p.u respectively.

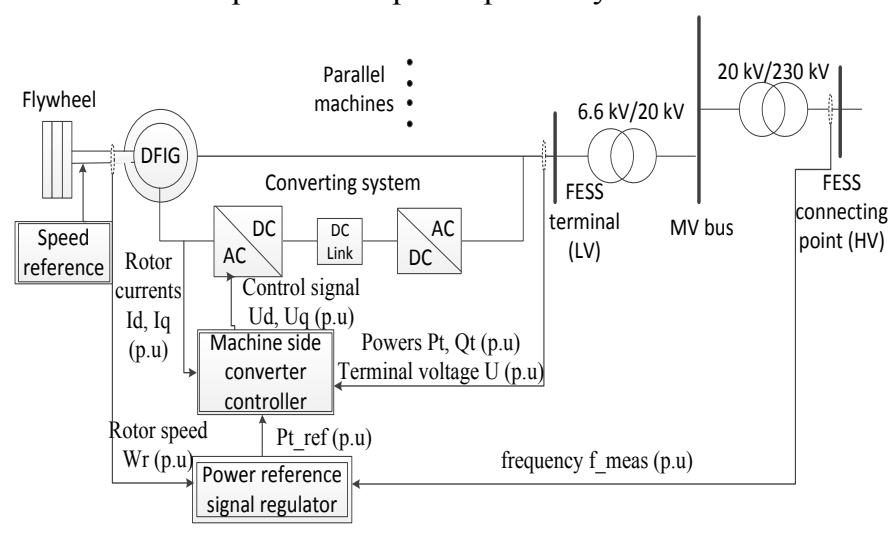

Fig. 2: Flywheel energy storage system

In order to have equal capabilities of absorbing and providing active power, the reference state of charge SOC of the flywheel is set at $50 \%$. The machine side converter, presented in Fig. 3, controls active and reactive power of FESS. Fig. 4 shows the power reference regulator used within the FESS in these studies. The power reference regulator monitors the system frequency and generates a signal to absorb or provide active power to the grid when the system 
frequency deviates from the nominal frequency. The power reference regulator also takes into consideration the SOC of the flywheel, active power provided by the flywheel decreases as the stored energy decreases.

The FESS has 'Select Switch' block to keep the rotor speed within the set limits. The operating logic of the 'Select Switch' is given in Table $\mathrm{I}$.

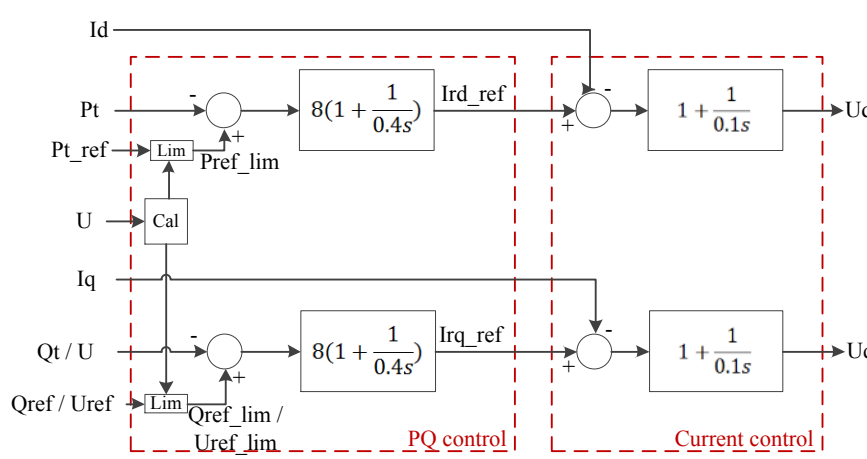

Fig. 3: Machine side converter control

\begin{tabular}{cccc}
\multicolumn{4}{c}{ TABLE I: OPERATING LOGIC OF SELECT SWITCH } \\
\hline $\begin{array}{c}\text { Rotor speed - } \\
\text { Wr(p.u) }\end{array}$ & $\mathbf{W r}>\mathbf{1 . 3}$ & $\mathbf{1 . 3}>\mathbf{W r}>\mathbf{0 . 7}$ & $\mathbf{W r}<\mathbf{0 . 7}$ \\
\hline $\begin{array}{c}\text { Frequency }<\mathbf{1} \\
\text { p.u }\end{array}$ & $\begin{array}{c}\text { Provides active } \\
\text { power }\end{array}$ & $\begin{array}{c}\text { Provides active } \\
\text { power }\end{array}$ & $\begin{array}{c}\text { Cannot provide } \\
\text { active power }\end{array}$ \\
\hline $\begin{array}{c}\text { Frequency }>\mathbf{1} \\
\text { p.u }\end{array}$ & $\begin{array}{c}\text { Cannot absorb } \\
\text { active power }\end{array}$ & $\begin{array}{c}\text { Absorbs active } \\
\text { power }\end{array}$ & $\begin{array}{c}\text { Absorbs active } \\
\text { power }\end{array}$ \\
\hline
\end{tabular}

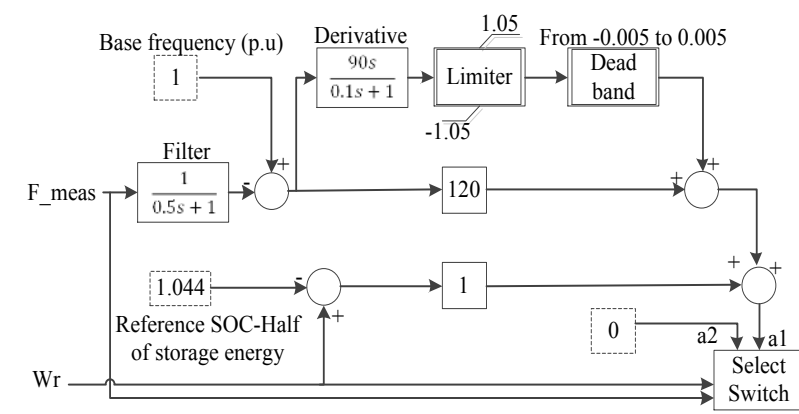

Fig. 4: Power reference regulator

In this work, multiple parallel units are installed to form a 1000MVA FESS plant. In Table II, the parameters of a single FESS unit are presented.

TABLE II: PARAMETERS OF FESS

\begin{tabular}{c|c|c|c} 
TABLE II: PARAMETERS OF FESS \\
\hline Stator resistance (p.u) & 0.02 & Rotor leakage reactance (p.u) & 0.02 \\
Stator leakage reactance(p.u) & 0.08 & Nominal voltage (kV) & 6.6 \\
Magnetizing reactance (p.u) & 3.5 & Power rating (MVA) & 4 \\
Rotor resistance (p.u) & 0.02 & Inertia constant (s) & 15 \\
\hline
\end{tabular}

B Battery Energy Storage System (BESS)

DIgSILENT PowerFactory provides a built in model for battery energy storage system. Fig. 5 illustrates BESS used in this work. Battery is modelled as a voltage source with internal impedance. The battery voltage varies linearly with SOC, the internal resistance is assumed to be constant, and the capacity is assumed as constant. With these three assumptions [12], the battery model can be expressed as (2).

$$
\mathrm{U}_{\mathrm{DC}}=\mathrm{U}_{\max } \mathrm{SOC}+\mathrm{U}_{\min }(1-\mathrm{SOC})-\mathrm{IZ}_{\mathrm{i}}
$$

$\mathrm{U}_{\mathrm{DC}}$ is terminal DC voltage of the battery, $\mathrm{I}$ is charge discharge current, $\mathrm{U}_{\max } / \mathrm{U}_{\min }$ is the voltage of the fully loaded/discharged cell; $Z_{\mathrm{i}}$ is the battery internal resistance and SOC is the state of charge of the battery.

BESS supplies or absorbs power from the grid when the frequency deviates from the nominal value. The frequency control is a droop control which defines the active power reference signal according to frequency deviation measured at the terminal of connection. The PQ control is a PI controller.

The BESS provides or absorbs constant power depending on the reference signal until SOC of the battery reaches the threshold.The battery is recharged if SOC is under the threshold value. The initial SOC is set as 0.8 p.u.

Similar to FESS, a single BESS unit is rated at 50 MVA and to achieve larger power rating, parallel units are employed to form the BESS plant.

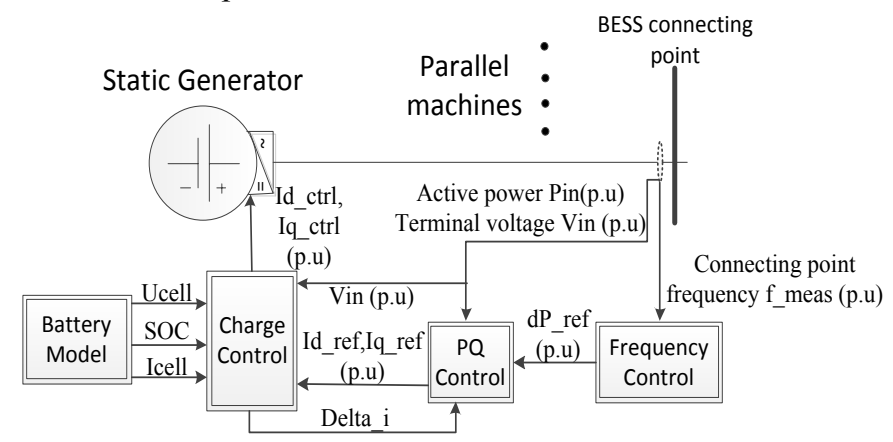

Fig. 5: BESS configuration with control scheme

\section{TEST SYSTEM AND CASE STUDIES}

\section{A. Test System}

The test network within these studies is a modified version of the 16-machine, 68-bus New England Test System (NETS) and New York Power system (NYPS), presented in Fig. 1 [13]. This IEEE 16 machine, 68 bus reduced order network consists of five areas: NETS includes generators G1 - G9, G10 - G13 form NYPS, and three neighboring areas are represented by equivalent generators G14, G15, and G16. At the nominal loading, as given in [13], powers are transferred from NETs and neighboring areas to NYPS through eight tie-lines.

Generators G2-G8 and G10-G13 are under slow DC excitation (IEEE-DC1A) whilst G1, G9, and G13-G16 have fast acting static exciter (IEEE-ST1A). G9 and G16 also have power system stabilizer (PSS). All generators in the network are equipped with governors. Generators G1 and G2 include 
GAST speed governor, G5 and G9 are equipped with IEEEG3 (hydro turbine) governor systems, and G3, G6, G7, G8, G10G16 incorporate IEEEG1 (steam turbine) speed governors. The synchronous generators are represented by sixth order dynamic models. Transmission lines are modeled with standard $\pi$ circuit, and loads are modeled as constant impedances [13].

\section{B. Case Studies}

In order to compare two storage technologies the following study cases are developed:

- Effect of different types of disturbance on the system frequency response with each type of ESS

- Comparison of a bulk energy storage system and distributed energy storage system

- Effect of network loading on system frequency with two types of ESS

\section{Simulations Results}

\section{A. Effect of different types of disturbance}

\section{1) Three phase fault}

The most sensitive fault location in NETs area is determined by introducing the fault at each bus (except generator and transformer bus). The bus 68 is found to be the most sensitive fault location. Therefore, a three phase fault is introduced at bus 68 and cleared after $145 \mathrm{~ms}$. ESS is placed on bus 58 . Simulations are performed without and with each type of storage technology. Frequency responses at line 41, line 44 and each generator bus are monitored.

Fig. 6 shows the system frequency at line 41 and frequency of generator G5.
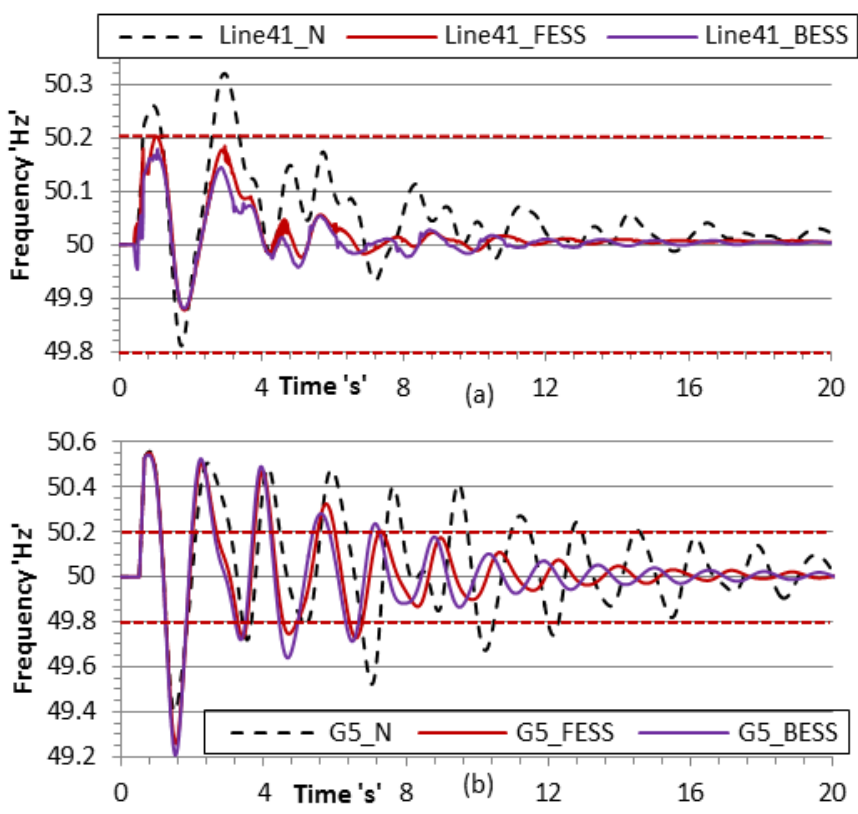

Fig. 6: Frequency responses with three phase fault with and without storage (a) Line 41 (b) Generator G5

It can be observed that the frequency response on line 41 is improved with each ESS technology, FESS and BESS. With each ESS frequency deviation is smaller, and the time is reduced when the frequency excursions are outside the operational limits.

In case of G5, the initial drop in the frequency of G5 is greater when storage is present in the network but settling time is reduced with both types of ESS. Frequency responses of G4 - G7 show the similar trend. The frequency response of generators G1-G3 and G8-G9 is improved with ESS, initial drop in the frequency and settling time is reduced.

\section{2) Generator Outage event}

Frequency excursions due to generator outage are also analyzed without and with each type of ESS. Generator G7 is taken out at $0.5 \mathrm{~s}$ and the system frequency at line 41 , line 44 and all generator buses is recorded. The traces of the frequency at line 41 and G5 without and with each type of ESS are presented in Fig. 7.

It can be noticed that improvement in the initial drop of the frequency with both types of energy storage systems is almost the same, but the settling frequency with BESS is closer to the nominal frequency. It could be due to different frequency control for FESS and BESS. As explained earlier, the power reference signal of FESS does not only depend on the frequency deviation, but takes into account SOC of FESS. Therefore, the active power support from FESS decreases with time. On the other hand, BESS continues to supply the same amount of power proportional to the frequency deviation until the minimum value of SOC is reached.
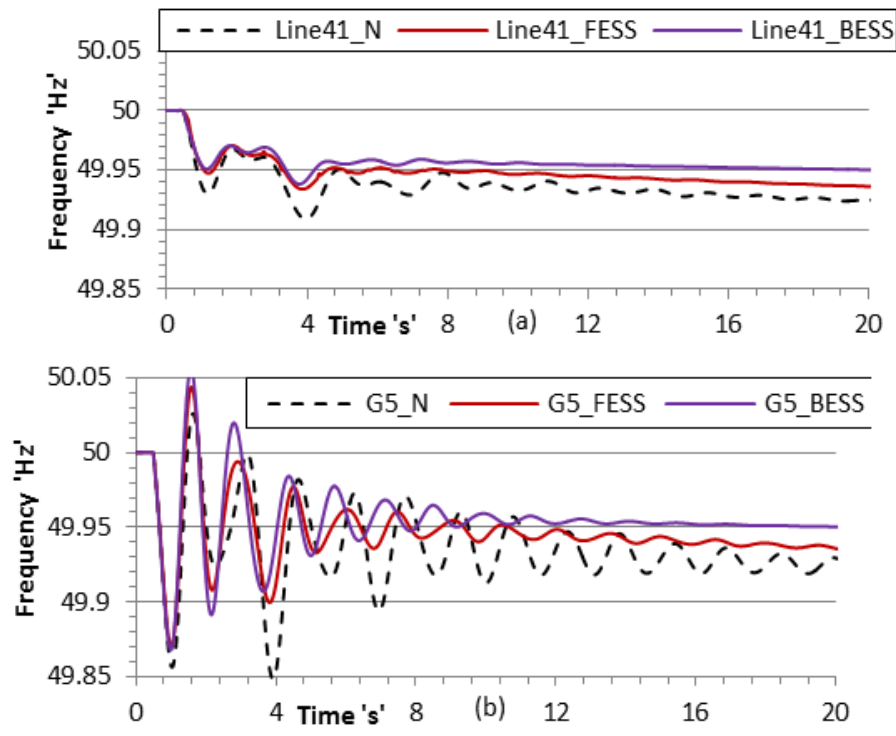

Fig. 7: Frequency responses with generator outage with and without storage (a) Line 41 (b) Generator G5

\section{3) Load Variation}

Loads at buses 20,24, 28, 55, 59, 67 and 68 in NETS 
(highlighted by red triangle in Fig. 1) are varied simultaneously by $22 \%$. Fig. 8 shows frequency responses of line 41 and generator G5.

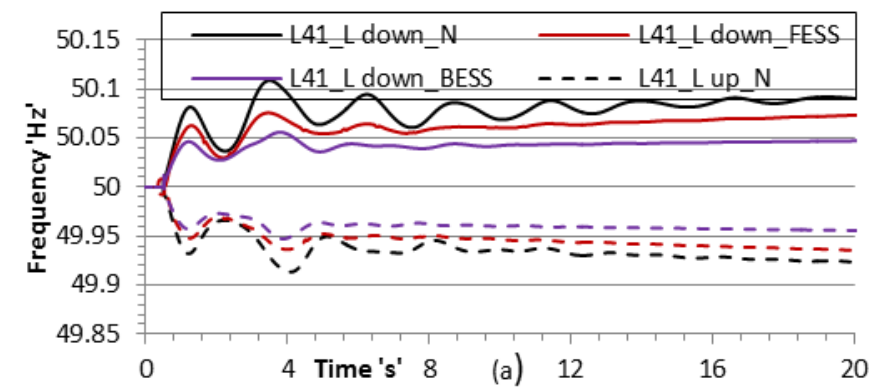

The system frequency at line 41 and generator G5 frequency, both are improved with FESS and BESS. The improvement in frequency excursions is better with BESS compared to FESS.

Fig. 8: Frequency responses with step increase and decrease in multiple loads (a) Line 41 (b) Generator G5

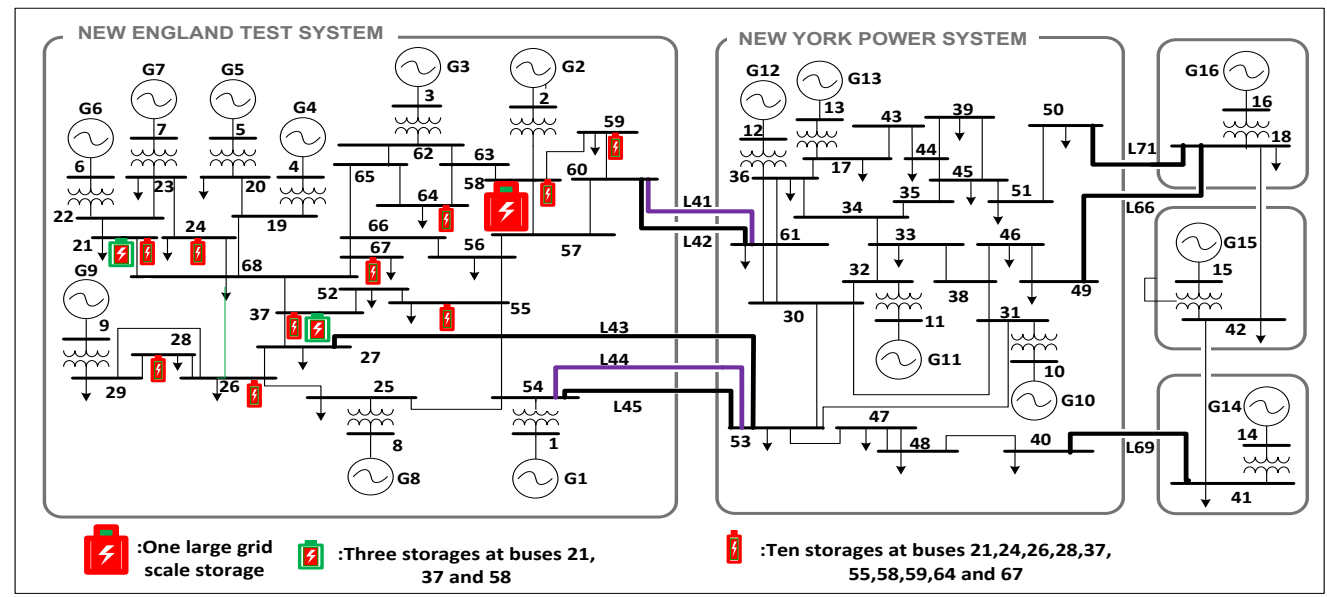

Fig. 9: Distributed energy storage placement in the test network
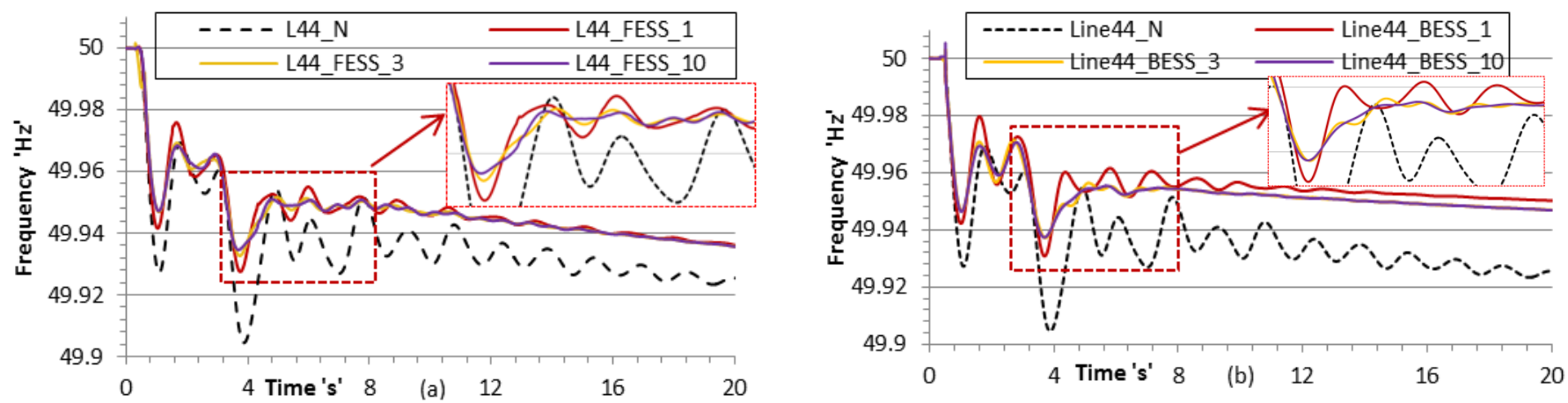

Fig. 10: Frequency response of line 44 with a bulk and distributed ESS (a) FESS (b) BESS

\section{B. Effect of different modes of storage deployment}

Two more case studies are developed to compare the frequency support offered by different modes of deployement of ESSs. The performance with one bulk ESS discussed above is further compared with results obtained using two different configurations of distributed energy storage of the same capacity. The distributed storage arrangement is illustrated in

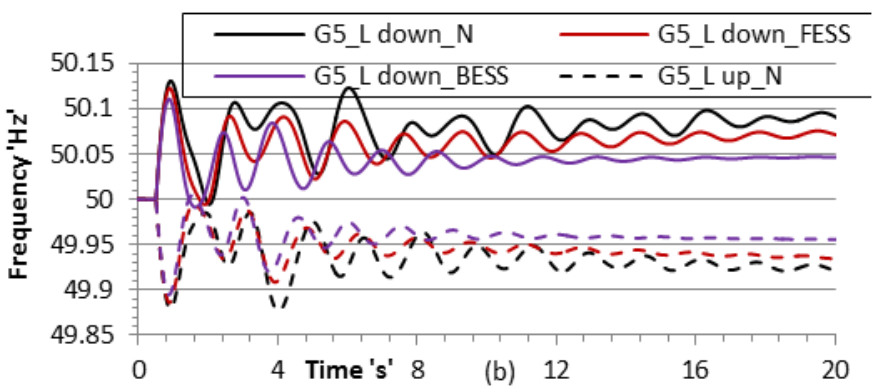


- Ten 100MVA ESSs are connected at buses 21, 24, 26, 28, $37,55,58,59,64$ and 67 . Frequency excursions caused by the generator G7 outage are recorded. Simulations are performed with 10 BESS in NETs and repeated for 10 FESS.

Frequency response for bus 44 is presented in Fig. 10 with one bulk EES, three EES and 10 EES. In this case frequency response on line 44 rather than line 41 is presented as the effect of different storage location arrangement is slightly more clear on line 44 .

It can be observed that frequency excursions are more damped, initial drop in the frequency and settling time is reduced with distributed storage arrangements. It is true for both BESS and FESS. Frequency deviation is reduced by $24.08 \%$ with one bulk FESS and this percentage is improved to around $29.54 \%$ with distributed FESS placement. For BESS, the percentage reduction in frequency deviation with one bulk ESS is $27.54 \%$ which increases to $34.29 \%$ with distributed BESS arrangement. It is to be noted that these numbers are only given here for the purpose of comparison of different modes of deployment of ESS.

\section{Effect of different operating conditions}

This section investigates the influence of the network loading on frequency excursions in the presence of distributed energy storage. 10 ESS in total- 5 FESSs and 5 BESSs are installed in the network.

Studies are performed with 1.1 p.u and 0.3 p.u loading of the network. For 1.1 p.u loading, loads in the network are increased by $10 \%$ and optimal load flow is performed. For 0.3 p.u loading the loads in the network are decreased by $70 \%$ and optimal load flow is run to determine the loading of each generator.

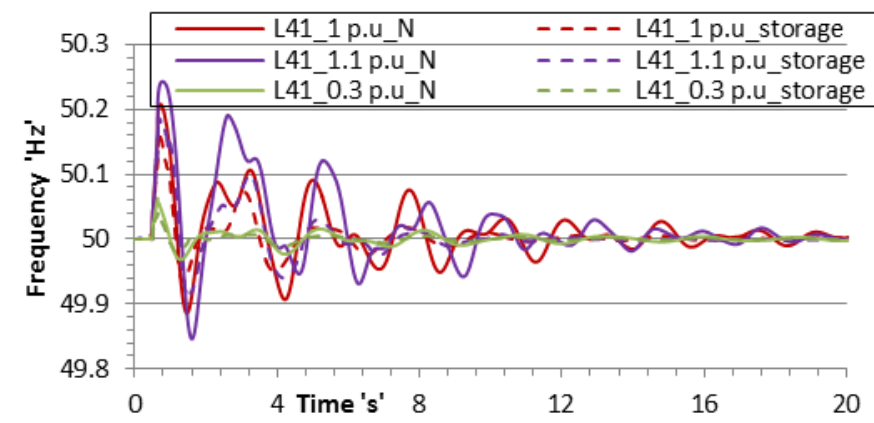

Fig. 11: Frequency response of tie-line 41 of different operating conditions

A three phase fault is introduced at bus 68 and cleared after $145 \mathrm{~ms}$. Frequency excursions at bus 41 are recorded for three loadings of the network, 1.1 p.u, 1 p.u and 0.3 p.u and are presented in Fig. 11. The percentage reduction in the frequency deviation with ESS is nearly the same for three studied loadings of the network. As expected the frequency excursions are bigger at higher loading of the network and significantly lower at 0.3 p.u loading. Without storage in the network, the system takes approximately $20 \mathrm{~s}$ when frequency oscillations at each loading level are overlapped. Presence of ESS decreases this time to nearly $8 \mathrm{sec}$. In other words, the effect of higher loadings of generators is lessened with ESS in the network.

\section{CONCLUSIONS}

This paper presented the comparative analysis of two types of energy storage system with contribution to the system frequency response. Case studies examined the performance of two energy storage technologies with three phase fault, generator outage and variation in loads. It is observed that both BESS and FESS with suitable control can effectively reduce the system frequency oscillation following all three studied network disturbances. Although, in case of a three phase fault, the initial frequency deviation became bigger for a few generators, the settling time reduced significantly.

It is observed that the distributed storage placement of the same storage capacity facilitates better frequency support compared to the bulk storage placement. The frequency response of the system is improved when one bulk storage split into three units at different buses. However, when three plants are replaced by ten plants on different buses, no further improvement in the system frequency is observed.

Network operating at higher loadings results in bigger frequency excursions following a three phase fault. Both types of energy storage technologies reduce the effect of network loading by decreasing the initial deviation in the frequency and damping the frequency excursions. The frequency excursions due to three phase fault for three studied loading of the network overlap each other after $7.5 \mathrm{~s}$ of fault occurrence.

\section{REFERENCES}

[1] Helder Lopes Ferreira, Raquel Garde, Gianluca Fulli, Wil Kling, and Joao Pecas Lopes, "Characterisation of electrical energy storage technologies," Energy, vol. 53, pp. 288-298, 2013.

[2] S. K. Aditya and D. Das, "Application of battery energy storage system to load frequency control of an isolated power system," International Journal of Energy Research, vol. 23, pp. 247-258, 1999.

[3] S. Kalyani; S. Nagalakshmi; R. Marisha, "Load frequency control using battery energy storage system in interconnected power system," Computing Communication \& Networking Technologies (ICCCNT), 2012 Third International Conference, pp.1-6, 26-28 July 2012.

[4] M. Aghamohammadi and H. Abdolahinia, "A new approach for optimal sizing of battery energy storage system for primary frequency control of islanded Microgrid", International Journal of Electrical Power \& Energy Systems, vol. 54, pp. 325-333, 2014.

[5] F. Díaz-González, "Power Smoothing of DFIG Wind Turbines with Flywheel", in EWEA 2011, Brussels, Belgium, 2011.

[6] R. Takahashi, J. Tamura; "Frequency Stabilization of Small Power System with Wind Farm by Using Flywheel Energy Storage System," Diagnostics for Electric Machines, Power Electronics and Drives, 2007. 
SDEMPED 2007. IEEE International Symposium, pp.393-398, Sept. 2007.

[7] J. Feng, G. Wang, L. Fu, "Applying flywheel energy storage system to integrated power system for power quality and stability enhancement", Electrical Machines and Systems (ICEMS), 2011 International Conference, pp.1-5, 20-23 Aug. 2011.

[8] R. Peña-Alzola, R. Sebastian, J. Quesada, "Review of flywheel based energy storage systems," Power Engineering, Energy and Electrical Drives (POWERENG), 2011 International Conference, pp.1-6, 11-13 May 2011.

[9] F. Islam, H. Hasanien, A. Al-Durra, "A new control strategy for smoothing of wind farm output using short-term ahead wind speed prediction and Flywheel energy storage system," American Control Conference (ACC), 2012, pp.3026-3031, 27-29 June 2012.

[10] G. Suvire, M. Molina and P. Mercado, "Improving the Integration of Wind Power Generation Into AC Microgrids Using Flywheel Energy Storage," Smart Grid, IEEE Transactions, vol.3, no.4, pp.1945-1954, Dec. 2012.

[11] S. Samineni, B. Johnson, H. Hess and J. Law, "Modeling and analysis of a flywheel energy storage system for voltage sag correction," Electric Machines and Drives Conference, 2003. IEMDC'03. IEEE International, vol.3, pp.1813-1818, 1-4 June 2003.

[12] B. Idlbi, "Dynamic Simulation of a PV-Diesel-Battery Hybrid Plant for off grid Electricity Supply", MSc, University Of Kassel, 2012.

[13] B. Pal and B. Chaudhuri, Robust control in power systems. New York: Springer, 2005. 